\title{
Prospective randomised trial of standard pressure versus low pressure laparoscopic cholecystectomy in a tertiary care hospital from Kolkata: Our experience
}

\author{
Bikash Chandra Ghosh ${ }^{1 *}$, Ambar Gangopadhyay ${ }^{2}$ \\ ${ }^{1,2}$ Associate Professor, Department of General Surgery, R. G. Kar Medical College Kolkata
}

\section{A B S T R A C T}

Background: Laparoscopic cholecystectomy (LC), the procedure of choice for symptomatic gall stone disease. An emerging trend is to perform Low pressure pnuemoperitonium laparoscopic surgery as it has additive advantages over standard pressure to avoid complications while providing adequate working space. Aims and Objectives: The current study was designed with an aim to compare the advantage of low pressure pneumoperitoneum vs standard pressure pneumoperitoneum in laparoscopic cholecystectomy. Materials and Methods: The study was conducted in the department of General Surgery in R.G.Kar Medical College from January 2014 to June 2015. A total of 52 patients with symptomatic gall stone disease were recruited, 26 patients in each group randomly. Some intraoperative and post-operative parameters were studied. Results: All the intra-operative (IO) cardio-respiratory parameters (Pulse, Mean Arterial Pressure (MAP), End tidal $\mathrm{CO}_{2}, \mathrm{spO}_{2}$ ) were recorded just before incision, 20 minutes intra-operatively and before reversal of general anesthesia (GA). The IO parameters in our study, were found to be significant only at 20 minutes 10 and before reversal of GA. The post-operative (PO) parameters (Pulse, MAP, Respiratory rate, $\mathrm{spO}_{2}$ ) and pain by VAS score at 6 hours, 12 hours and 24 hours post-operatively were studied. In PO period, we observed significant differences at 2 hours post-operatively in all parameters except MAP. There was significant difference in pain at 6, 12 and 24 hours when compared in both groups. The shoulder tip pain (STP) and 2 hours PO nausea and vomiting were found to be significantly higher in Standard pressure Laparoscopic cholecystectomy (SPLC) compared to Low pressure Laparoscopic cholecystectomy (LPLC). The operative time, duration of hospital stay and return to normal life after surgery though had differences but it was statistically insignificant. Conclusion: Low pressure laparoscopic surgery is safe with least post operative complications when performed by experienced surgeons even in patients of ASA III.

Key words: Laparoscopic cholecystectomy; Standard pressure pneumoperitoneum; Low pressure pneumoperitoneum; Operative time; Post-operative pain; Shoulder tip pain

\section{INTRODUCTION}

Biliary diseases known since ages constitute a major portion of digestive tract disorders world over and Gallstone disease remains to be the major cause of abdominal morbidity and mortality. ${ }^{1}$ Laparoscopic cholecystectomy (LC) has become the treatment of choice in symptomatic gallstones. ${ }^{2}$ During LC adequate working space is required in the abdomen for good exposure that contributes to satisfactory results and patient safety. ${ }^{3}$ Common methods to create working space in the abdomen are pneumoperitoneum and abdominal wall lifting methods such as the laparotensor and laparolift. ${ }^{4}$ It enables to identify important anatomic structures and when no progress is made over a set period of time, a conversion to an open procedure is usually indicated. The pneumoperitoneum created by the gas (commonly by the $\mathrm{CO}_{2}$ ) is associated with 
gross hemodynamic changes, post-operative complications like shoulder pain and is considered unsafe in ASA class III and above. ${ }^{5}$ The current trend is to employ low pressure laparoscopic cholecystectomy (LPLC). While standard pressure pneumoperitoneum, employs a pressure range of $12-14 \mathrm{~mm} \mathrm{Hg}$, the low pressure pneumoperitoneum ranges from 7-10 $\mathrm{mm} \mathrm{Hg}$. This technique was attempted to lower the impact of pneumoperitoneum like $\mathrm{CO}_{2}$ embolism, vasovagal reflex, cardiac arrhythmia, hypercarbic acidosis and minimizes haemodynamic effect of insufflation. ${ }^{6}$ However, the lower pressures involved in the LPLC might result in a less than adequate exposure of the operating space. This might result in longer than usual operating time, higher rate of intraoperative complications and also possibly higher frequency of conversion to standard pressure laparoscopic cholecystectomy (SPLC) or open cholecystectomy. The current study proposes to compare the advantages of low pressure with standard pressure pneumoperitoneum in LC.

\section{MATERIALS AND METHODS}

The current study was a prospective single centre comparative study which was conducted in department of General Surgery in R.G. Kar Medical College from January 2014 to June 2015. Fifty-two patients with symptomatic gall stone disease were recruited as per the inclusion criteria of the study. Of which 26 patients were randomly allocated in each group namely SPLC and LPLC. The data was recorded during operation, post operatively and at follow up in OPD for 3 months.

\section{Inclusion criteria}

1. Uncomplicated symptomatic cholelithiasis.

2. On pre-operative ultrasound with normal common bile duct.

\section{Exclusion criteria}

1. Acute cholecystitis and choledocholithiasis.

2. Gangrene and empyema and malignancy of gallbladder, biliary-enteric fistulae.

3. Chronic obstructive pulmonary disease, Coronary artery disease, congestive heart failure, asthma

4. Patients with Cirrhosis, Significant portal hypertension, Pregnancy, Obesity, uncorrectable coagulopathies, generalized peritonitis.

5. Previous history of upper abdominal procedures

6. All cases converted to open method were excluded. In the study groups no case was converted.

\section{Parameters studied}

Data collected with regards to the following parameters:

\section{Intra-operative}

Operative time (starting from time of incision to time of closure in minutes), Intra operative cardio-respiratory stability monitoring parameters like pulse, Mean arterial pressure (MAP), End tidal $\mathrm{CO}_{2}\left(\mathrm{ETCO}_{2}\right)$ and monitoring and Oxygen saturation (\%) before incision, after 20 minutes intra operatively and before reversal from GA.

\section{Post-operative}

Post operative cardio-respiratory stability monitoring like pulse, Mean arterial pressure (MAP), respiratory rate and Oxygen saturation ( $\%$ ) were recorded 2 hours post operatively.

b.i.) Complications like nausea and vomiting were recorded at 2 hours post operatively.

b.ii.) Post operative pain score was analyzed by using the Visual analogue scale (VAS) at $6 \mathrm{hrs}, 12 \mathrm{hrs}$ and $24 \mathrm{hrs}$ post operatively.

c) Post operative recovery and hospital stay (in days)

d) Post operative return to normal activity in days.

\section{STATISTICAL ANALYSIS}

The data of SPLC and LPLC were analysed using ' $t$ ' test, $\chi^{2}$ and analysis of variance wherever applicable. The statistical analysis included sex, mean age, body mass index, operative time, postoperative pain assessed by the Visual Analogue Scale of Pain (VAS) including the incidence of shouldertip pain, postoperative hospital stay, return to normal activity following the operation. $\mathrm{p}<0.05$ was considered as indicative of significance.

\section{RESULTS}

The current study included fifty-two patients with symptomatic gall stone disease, of which 26 patients were randomly allocated in each group namely SPLC and LPLC. Table 1 shows the demographic variables of the study subjects of both groups. The mean operating time in both groups is shown in Table 2.

Intra operative parameters like MAP, $\mathrm{ETCO}_{2}$, Pulse and Oxygen saturation (\%) were recorded and analyzed in both groups at subsequent three interval of time namely before incision, 20 minutes intra-operatively and before reversal

\begin{tabular}{|c|c|c|c|}
\hline Parameters & SPLC $(n=26)$ & LPLC $(n=26)$ & $P$ value \\
\hline $\begin{array}{l}\text { Age (years) } \\
\text { mean } \pm S D\end{array}$ & $39.30 \pm 12.93$ & $42.80 \pm 10.45$ & 0.78 (NS) \\
\hline $\begin{array}{l}\mathrm{BMI}\left(\mathrm{kg} / \mathrm{m}^{2}\right) \\
\text { mean } \pm \mathrm{SD}\end{array}$ & $23.83 \pm 0.68$ & $23.30 \pm 0.55$ & 0.52 (NS) \\
\hline \multicolumn{4}{|l|}{ Gender } \\
\hline Male & 2 & 2 & 1.00 (NS) \\
\hline Female & 24 & 24 & \\
\hline
\end{tabular}


from GA (Table 3). The post-operative parameters like pulse, MAP, respiratory rate and oxygen saturation (\%) were recorded 2 hours post-operatively. The pain score (by VAS) were recorded at 6 hours, 12 hours and 24 hours in post operative cases (Table 3 ).

The intra-operative parameters in our study, were found to be significant only at 20 minutes intra-operatively and before reversal of GA in all the parameters. In postoperative period, we observed significant differences at 2 hours post-operatively in all parameters except mean arterial pressure. There was significant difference in pain at 6 hours, 12 hours and 24 hours when compared in both groups (Table 3).

Post operative Shoulder pain was analyzed and was recorded in the six cases of SPLC group but none has shoulder pain in LPLC group. The differences in pain

\begin{tabular}{lcc}
\multicolumn{3}{l}{ Table 2: Comparison of operative time (in } \\
minutes) from start of incision to closure of skin \\
\hline \multicolumn{4}{l}{ Type of operation } & $\begin{array}{c}\text { Mean Operating } \\
\text { time (mins) } \pm \text { SD }\end{array}$ & P value \\
\hline SPLC $(n=26)$ & $47.69 \pm 13.50$ & $0.1354(\mathrm{NS})$ \\
LPLC $(n=26)$ & $53.46 \pm 13.91$ & \\
\hline
\end{tabular}

among both groups was statistically significant $(\mathrm{p}=0.02)$ (Figure 1). The 2 hours post operative nausea vomiting was found among 10 cases of SPLC group and only 2 cases in LPLC group, which was also statistically significant with a p-value of 0.01 (Figure 2).

The post operative average hospital stay in LPLC group was 2.65days whereas in SPLC group it was 2.18 days, though the differences were not significant (Table. 4). Similarly the average return to the normal activity in SPLC group was 5.62 days when compared to LPLC group which was 6.1 days, again an insignificant difference.

\section{DISCUSSION}

The current study was a randomized prospective single centered study conducted at the Department of General Surgery, R.G. Kar Medical College and Hospital, Kolkata for a period of one and half year from January 2014 to June 2015. The numbers of patients was 52 and were equally allocated in both SPLC and LPLC groups randomly. Their age ranged from 24 years to 68 years and was selected irrespective of age/sex matched cases in both groups. Gastric decompression was done by Ryle's tube in LPLC group, to allow collapse of stomach during operation and

Table 3: Comparison of Intra-operative and post-operative parameters

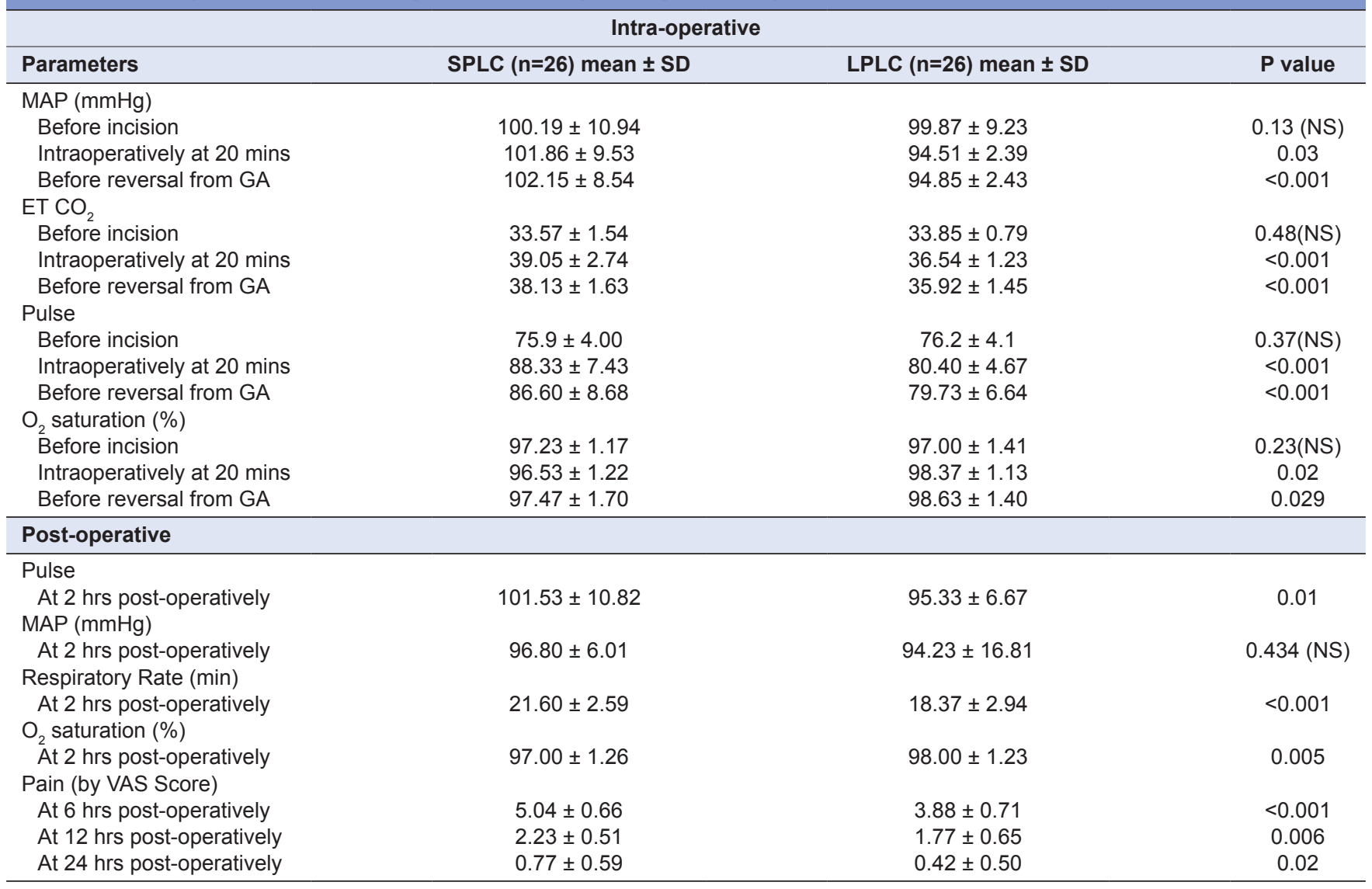




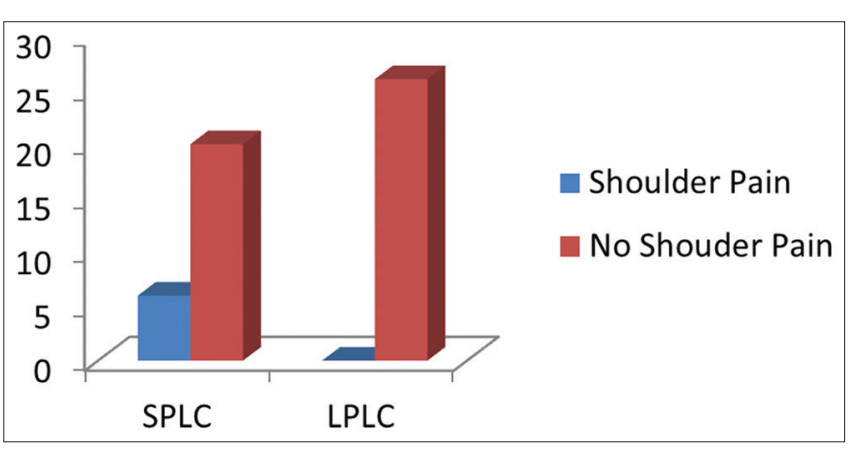

Figure 1: Analysis of Shoulder pain in both groups

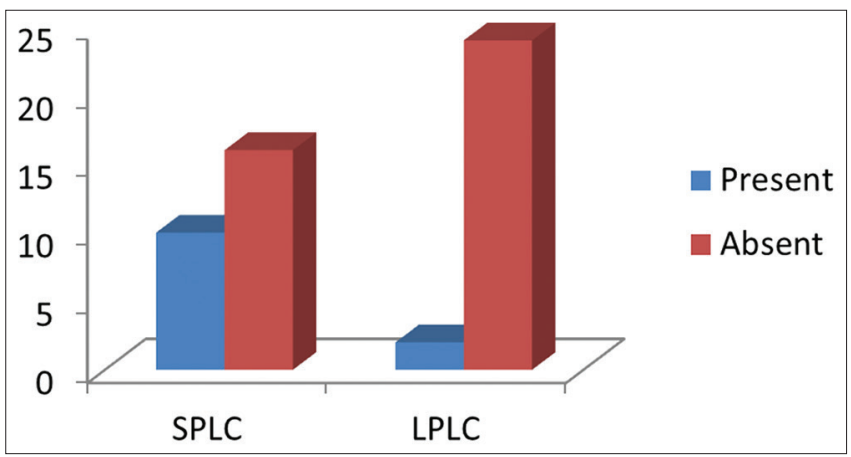

Figure 2: Analysis of 2 hours Post operative nausea and vomiting in both groups

\begin{tabular}{lccc}
$\begin{array}{l}\text { Table 4: Comparison of hospital stay and return } \\
\text { to normal activity (in days) }\end{array}$ & P value \\
\cline { 2 - 3 } Parameters & \multicolumn{2}{c}{ Mean \pm SD } & \\
\cline { 2 - 3 } & SPLC ( $\mathbf{n = 2 6 )}$ & LPLC ( $\mathbf{n = 2 6 )}$ & 0.14 (NS) \\
\hline $\begin{array}{l}\text { Post operative } \\
\text { hospital } \\
\text { stay (days) }\end{array}$ & $2.18 \pm 0.99$ & $2.65 \pm 1.39$ & \\
$\begin{array}{l}\text { Return to Normal } \\
\text { Activity (days) }\end{array}$ & $5.62 \pm 1.30$ & $6.10 \pm 1.93$ & 0.26 (NS) \\
\hline
\end{tabular}

to create more intra-operative space. Most of the cases intra operatively had clear anatomy with minor omental adhesions.

The current study did not observe any significant differences in age, gender and BMI in both groups. In a prospective randomized study was carried out on 80 patients, the mean age of patients in the SPLC group was $44.8+9.7$ years and that in LPLC group was $44.1+11.1$ years. The difference was not statistically significant. Females formed $67.5 \%$ in SPLC group and 65\% in LPLC group. The difference was not however statistically significant. ${ }^{7}$ In another randomized case control study consisting of 80 patients in UPUMS, Etawah from January 2015 to July 2016. The mean ageof SPLC and LPLC patient were 30.18years and 34.75 years which was statistically not significant. ${ }^{8}$ In yet another prospective randomized double blind study involving 118 patients between the ages of 20 and 75 years, conducted at Dr. RML Hospital, New Delhi observed the mean age of the LPLC (39.75 years) and the mean age of the SPLC (38.61 years). In terms of age and gender, both groups were similar $(\mathrm{P}=0.586)$ and $(\mathrm{P}=0.769)$ respectively. ${ }^{9}$ The above mentioned studies concur with the finding of the current study were we observed the similar results.

The mean operative time in both groups was not significant in the current study. In a randomized prospective study from India for a period from July 2014 to October 2016, consisting of 50 patients observed, LPLC group had more operative time than SPLC but the difference was not statistically significant $(p=0.1) .^{3}$

In another prospective randomized trial conducted in Poland on 148 patients with uncomplicated, symptomatic cholelithiasis between May 2000 and December 2001. The operative time was similar in both groups (LP $55.7 \pm 8.6 \mathrm{~min}$ vs SP $51.9 \pm 8.3 \mathrm{~min}) .{ }^{10}$ The current study is in accordance with the findings of the above studies.

In our study we observed post-operative shoulder pain in six cases of SPLC group but no shoulder pain was observed among LPLC group. The differences in pain among both groups was statistically significant $(p=0.02)$. In a prospective randomized study was carried out on 80 patients. Shoulder tip pain was noted in 15 (37.5\%) of patients in SPLC group whereas only $5(12.5 \%)$ patients complained of shoulder tip pain in the LPLC group. This difference was statistically significant $(\mathrm{P}=0.010){ }^{7}$

In another prospective randomized double blind study was conducted involving 118 patients between the ages of 20 and 75 years at Dr. RML Hospital, New Delhi, the mean visual analogue pain score of postoperative shoulder tip pain was significantly less intense in the low pressure group at 6,12, 24 hours than that recorded in the standard pressure group $\left(\mathrm{P}<0.001\right.$ by unpaired t-test). ${ }^{?}$

In a study in Poland among 148 consecutive patients, the incidence of shoulder-tip pain was 2.1 times lower afterLPLC than observed in SPLC and the difference in pain score was statistically significant $(\mathrm{p}<0.05) .{ }^{10}$

Sarli et $\mathrm{al}^{11}$ also observed similar findings in prospective randomized trial among ninety consecutive patients undergoing laparoscopic cholecystectomy. In their study fourteen patients $(32 \%)$ in SPLC group and five patients $(11 \%)$ in LPLC group complained of shoulder pain and the differences was significant $(\mathrm{P}<0.05)$. In another prospective randomized double blind study carried out at MMU, Department of Surgery, Solan among 50 patients also observed only $8 \%$ incidence of pain in shoulder tip in LPLC group when compared to SPLC which was $32 \%$ and 
was statistically significant $(\mathrm{p}=0.012) .{ }^{12}$ The observation from the above studies conforms to our observations.

In another randomized prospective study conducted in Rajkot India, from July 2014 to October 2016, with a sample size of 50 patients also observed lower postoperative pain referred to the tip of the right shoulder in LPLC group when compared to SPLC group though the difference was not statistically significant ${ }^{3}$ which is not similar to the findings of the current study.

The End tidal $\mathrm{CO}_{2}\left(\mathrm{EtCO}_{2}\right)$ in the current study observed statistically significant difference at Inter-operatively 20 minutes and before reversal of GA. In a study conducted by Singh et al in Etawah, Uttar Pradesh the mean EtCO2 of patients in SPLC was found to be higher than that of LPLC at all the periods of observation except at $30 \mathrm{~min}$ after induction, differences in EtCO2 levels of patients of LPLC and SPLC were found to be statistically significant at all the periods of observation at and after $30 \mathrm{~min}$ of induction (i.e. $30 \mathrm{~min}, 40 \mathrm{~min}, 50 \mathrm{~min}, 60 \mathrm{~min}$ and at 2 hrs). The findings of this study is more or less similar to our study, though our observation intervals were different but the differences between $\mathrm{EtCO}_{2}$ of LPLC and SPLC group were statistically significant. ${ }^{2}$

The current study observed significant difference in postop pain at 6 hours, 12 hours and 24 hours post operatively. In a randomized prospective study by Gohil, ${ }^{3}$ the incidence and intensity of post-operative pain were significantly lower in LPLC group compared to SPLC group. At 6 hours the average pain score for patients who underwent LPLC group was 2.5 whereas it was 2.8 in SPLC though it was not significant difference among the group which our study observed at 6 hours. In 12 hours the average pain score was 2.6 in LPLC group whereas it was 2.7 in SPLC and the difference was statistically significant which conforms with our study findings. But again at 24 hours the average pain score between two groups was not significant as observed in our study. In a prospective study conducted by Zaman et $\mathrm{al}^{12}$ the average pain score in SPLC group was 5.72 and 0.92 in LPLC group and the differences was statistically significant (p0.012). Yet another study by Barczynski et a ${ }^{10}$ the mean post operative pain score was 6.18 lower after LPLCprocedure than SPLCand the difference amounted to $22.2 \%$ ( $p<0.005)$. In a prospective study conducted by Krishnegowda et al, ${ }^{9}$ the mean visual analogue pain score at 1 , 6,12 , and 24 hours was significantly higher inthe SPLC group than in the LPLC and the differences was highly significant $(\mathrm{P}<0.001)$. All the above mentioned studies are near to good agreement with the findings of the current study.

The current study observed the post-operative average hospital stay of 2.65 days in LPLC group when compared to SPLC group which was 2.18 days, though the differences in duration of hospital stay was not significant. Another study conducted by Gohil ${ }^{3}$ the average hospital stay for LPLC group was 1.92 days and for SPLC group it was 2.48 days. In the report of study by Singh et al, ${ }^{8}$ the mean duration of hospital stay was $1.7 \pm 0.6$ days in SPLC group and the mean duration of hospital stay was $1.4 \pm 0.5$ days in LPLC group which was statistically significant. Both the above two studies are not in agreement with the current study as we observed more days of hospital stay in LPLC than SPLC group.

In the current study the average days to return to the normal activity in SPLC group was 5.62 days when compared to LPLC group which was 6.1 days, but the differences was statistically insignificant. In the report by Herman et a ${ }^{10}$ the quality of life within seven days of operation was remarkably better among LPLC group than in SPLC group which was statistically significant $(\mathrm{p}<0.01)$.

The current study did not observe and intra-operative complications in both groups of patients. Similar findings were observed by the studies conducted by Zaman et al, ${ }^{10}$ Sarli et $\mathrm{al}^{11}$ and Barczynski et $\mathrm{al}^{12}$ where they reported no difference in intra-operative complications among both groups. However one of the study observed 43 patients $(72.9 \%)$ showed no intra-operative complications in the LPLC group but 11 patients (18.6\%) had bile spillage and 5 patients $(8.5 \%)$ had bleeding. Among the SPLC group, 3 patients (5.1\%) suffered intraoperative bleeding while bile spillage occurred in 12 patients (20.3\%). Though no significant difference between the two groups was observed in terms of intra-operative complications $(\mathrm{P}=0.758)$.

Though LPLC has several disadvantages like intra-operative difficulties, bit more operating time, especially when the society is fond of minimal invasive surgery, the laparoscopic cholecystectomy has advantages as it is being performed in a single scar with singleincision laparoscopic surgery (SILS) or even without any scar in the abdomen by NOTES still is considered surgery of choice keeping in mind the intra-operative and postoperative cardio-respiratory stability, it still stand safe procedure for the cardiorespiratory compromised patients undergoing laparoscopic cholecystectomy especially the ASA II and more.

\section{LIMITATIONS OF THE STUDY}

The limitation of the current study is single centered, small number of study subjects, operation by a single surgeon. The study did not observe any intra-operative findings like various gall bladder morphology (normal, distended, contracted), number of gall stones (single, multiple) and cholesterosis. Even the study didn't show any 
intra-operative complications (vascular injury, bile spillage) conversion rate from LPLC to SPLC during operation, use of NSAIDs in post operative phase and other parameters of blood gas analysis like $\mathrm{pH}, \mathrm{PCO}_{2}$ and $\mathrm{HCO}_{3}^{-}$which were not analyzed during the study.

\section{CONCLUSION}

LP pneumoperitoneum is superior to SP pneumoperitoneum with respect to lower postoperative problems, a lower incidence of shoulder-tip pain, smooth recovery and a better quality of life within a week following the operation. LP should be performed for LC in cases of uncomplicated symptomatic gallstones if done in experienced surgeons, it is feasible and safe.

\section{ACKNOWLEDGEMENT}

Post-graduate Trainees and all staffs of Department of Surgery, R.G.Kar Medical College, Kolkata.

\section{REFERENCES}

1. Kanthan R, Senger JL, Ahmed S and Kanthan SC, Gallbladder Cancer in the $21^{\text {st }}$ Century. Journal of Oncology 2015; Article ID 967472, 26 pages.

2. Schirmer BD, Edge SB, Dix J, Hyser MJ, Hanks JB and Jones RS. Laparoscopic cholecystectomy. Treatment of choice for symptomatic cholelithiasis. Ann Surg 1991; 213(6):665-676.

3. Gohil A. Comparison of low pressure versus standard pressure pneumoperitoneum for elective laparoscopic cholecystectomy in a tertiary care institute of western India. Int Surg J 2018;

\section{5(5):1776-1780.}

4. Ren $\mathrm{H}$, Tong $\mathrm{Y}$, Ding Xi-Bing, Wang $\mathrm{X}$, Jin Shu-Qing, Niu XiaoYin, et al. Abdominal wall-lifting versus $\mathrm{CO} 2$ pneumoperitoneum in laparoscopy: a review and meta-analysis. Int $\mathrm{J}$ Clin Exp Med 2014; 7(6): 1558-1568.

5. Hackett NJ, De Oliveira GS, Jain UK and Kim JY. ASA class is a reliable independent predictor of medical complications and mortality following surgery. Int J Surg 2015; 18:184-190.

6. Schietroma M, Pessia B, Stifini D, Lancione L, Carlei F, Cecilia EM, et al. Effects of low and standard intraabdominal pressure on systemic inflammation and immune response in laparoscopic adrenalectomy: A prospective randomised study. Journal of Minimal Access Surgery 2016; 12(2): 109-117.

7. Nabi S, Nazima S, Bashir Y, Beigh A, Bashir N and Angmo D. Low Pressure Pneumoperitoneum versus Standard Pressure Pneumoperitoneum in Laparoscopic Cholestectomy- An Experience. Int J Adv Res 2017; 5(8): 1771-1778.

8. Singh SP, Verma S, Pandey A, Shukla U, Gupta V, Singh P, et al. Comparative evaluation of hemodynamic and capnographic changes in low pressure versus normal pressure pneumoperitoneum in laparoscopic cholecystectomy. IntSurg J 2017; 4(8):2642-2647.

9. Krishnegowda U, Gupta AK, Sharma R, Gupta N and Durga CK. A Comparative Study Between Low and Normal Pressure. Pneumoperitoneum in Laparoscopic Cholecystectomy with Special Reference to Shoulder Tip Pain. Hellenic Journal of Surgery 2016; 88(1): 13-17.

10. Barczynski M and Herman RM. A prospective randomized trial on comparison of low-pressure (LP) and standard-pressure (SP) pneumoperitoneum for laparoscopic cholecystectomy. SurgEndosc 2003; 17: 533-538.

11. Sarli L, Costi R, Sansebastiano G, Trivelli M and Roncoroni L. Prospective randomized trial of low-pressure pneumoperitoneum for reduction of shoulder-tip pain following laparoscopy. $\mathrm{Br} \mathrm{J}$ Surg 2000; 87(9):1161-1165.

12. Zaman M, Chowdhary K and Goyal P. Prospective Randomized Trial of Low Pressure Pneumoperitoneum for Reduction of Shoulder Tip Pain following Laparoscopic Cholecystectomy: A Comparative Study. World J Lap Surg 2015; 8(1):13-15.

\footnotetext{
Authors Contribution:

BCG- Review of literature, manuscript preparation and data collection; AG- Concept and design of the study, manuscript preparation, statistical analysis, data interpretation, critical revision of manuscript.

Work attributed to:

Department of General Surgery, R.G. Kar Medical College, Kolkata.

Orcid ID:

Dr. Bikash Chandra Ghosh- (i) http://orcid.org/0000-0001-5708-9243

Dr. Ambar Gangopadhyay- (i) http://orcid.org/0000-0003-2160-9256

Source of Support: R.G. Kar Medical College, Kolkata.(All surgeries conducted in this Government Medical College), Conflict of Interest: None declared.
} 